\title{
Colonic Gallstone lleus: A Rare Case
}

\author{
Cristina Teixeira Ana Luisa Alves Isabelle Cremers \\ Gastroenterology Department, Centro Hospitalar de Setúbal, Setúbal, Portugal
}

\section{Keywords \\ Cholelithiasis · Colonic gallstone ileus}

\section{Ileus biliar cólico: um caso raro}

\section{Palavras Chave}

Colelitíase · Íleus biliar cólico

\section{Case Report}

A 72-year-old woman with a history of atrial fibrillation, arterial hypertension, thyroidectomy, and mitral insufficiency presented to the emergency department with nausea, vomiting, and abdominal pain for the last $24 \mathrm{~h}$. At physical examination, the patient had right upper abdominal pain and Murphy's sign. Abdominal ultrasound revealed gallstones, thickened gallbladder wall, and sonographic Murphy's sign. Blood tests showed normal liver tests and inflammatory parameters (INR 2.1). She was admitted for acute cholecystitis. Due to comorbidities, intravenous antibiotherapy was started and cholecystectomy was delayed until cardiac evaluation and anticoagulation correction. On the 6th day of hospitalization, the patient presented abdominal distension, hyperactive bowel sounds, and mild diffuse tenderness. CT scan demon-

\section{KARGER}

E-Mail karger@karger.com www.karger.com/pjg
(C) 2018 Sociedade Portuguesa de Gastrenterologia. Published by S. Karger AG, Basel

Karcer

Open access

This article is licensed under the Creative Commons AttributionNonCommercial-NoDerivatives 4.0 International License (CC BYNC-ND) (http://www.karger.com/Services/OpenAccessLicense) Usage and distribution for commercial purposes as well as any distribution of modified material requires written permission. strated a thickened gallbladder wall with fistula to the colonic hepatic flexure, and a gallstone of $2.2 \mathrm{~cm}$ in the sigmoid colon causing proximal gas distension of the bowel (Fig. 1). Colonoscopy revealed an impacted gallstone at $30 \mathrm{~cm}$ from the anal verge and adjacent mucosal ulceration ( 2 ulcers of $5 \mathrm{~mm}$ ). Attempted endoscopic removal with snare and basket was unsuccessful (Fig. 2). Due to colonic distension and higher surgical risk associated with the one-stage procedure, the patient underwent enterolithotomy and cholecystectomy was delayed and performed 2 months later, without complications.

\section{Discussion}

Gallstone ileus is responsible for 1-4\% of cases of intestinal obstruction and occurs predominantly in females [1]. Biliary-enteric fistulas occur in the setting of inflammation, as acute cholecystitis and gallstones must be at least $2-2.5 \mathrm{~cm}$ in diameter to cause obstruction. The most common site of impaction is the terminal ileum and the ileocecal valve. Colonic gallstone ileus occurs in $4 \%$ of the cases, mostly at the level of the sigmoid colon [2]. Clinical presentation of gallstone ileus depends on the site of impaction and may include abdominal pain and distension, nausea, vomiting, and constipation. Diagnosis is difficult and in many cases, it is intraoperative. CT of the abdomen 


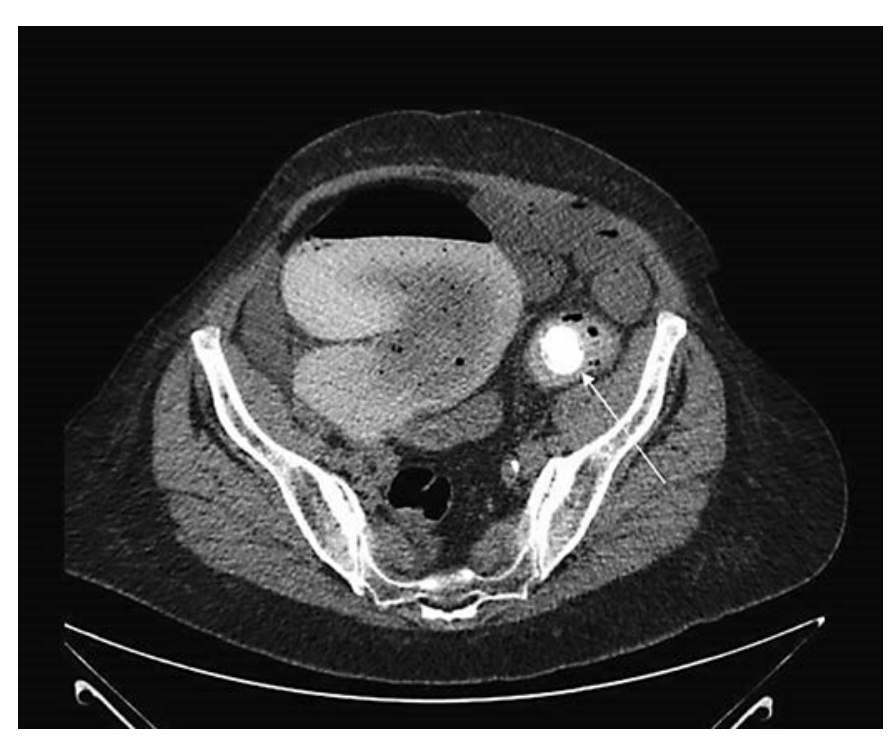

Fig. 1. CT scan: gallstone (arrow) in the sigmoid colon causing proximal gas distension of the bowel.

and pelvis remains the gold standard with sensitivity and specificity rates of 3 and $100 \%$, respectively [1]. The classical radiological triad as described by Rigler et al. [3] includes pneumobilia, dilated small bowel, and aberrant gallstone location. Surgery is the mainstay of treatment. Methods of approach include: enterolithotomy alone (with or without a sequential cholecystectomy) or enterolithotomy, cholecystectomy, and fistula repair as a onestage procedure. The one-stage procedure is related to higher perioperative morbidities and mortality [4]. Endoscopic retrieval of the stone may be attempted but is rarely successful. Other approaches include extracorporeal or electrohydraulic lithotripsy [4].

\section{Statement of Ethics}

This study did not require informed consent nor review/approval by the appropriate ethics committee.

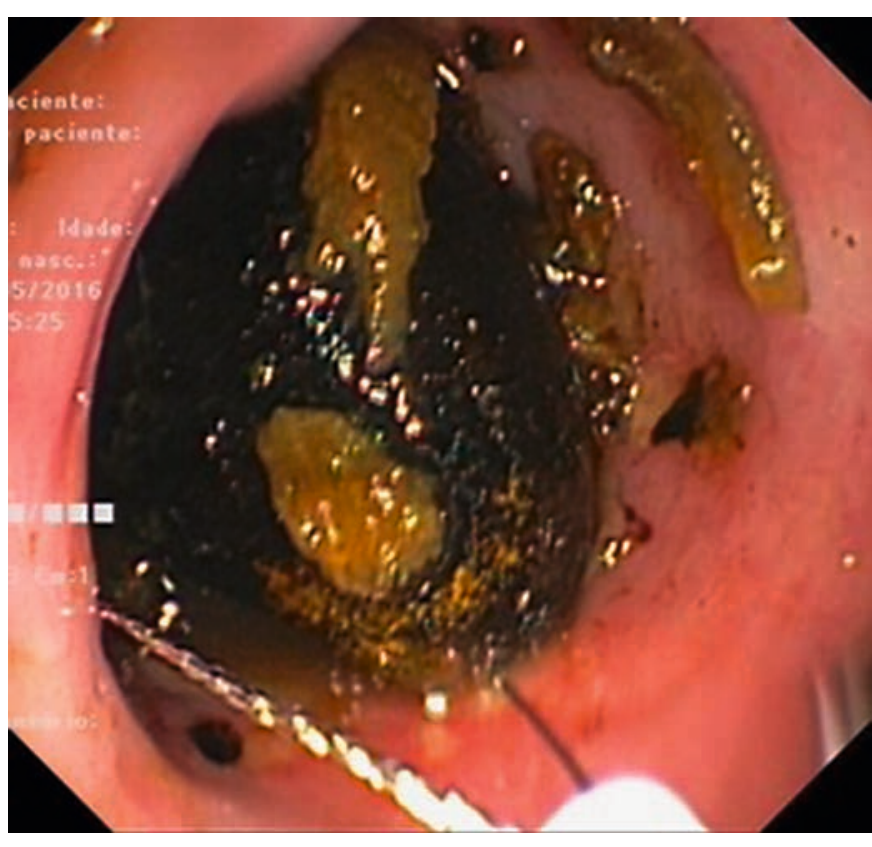

Fig. 2. Impacted gallstone in the sigmoid colon: endoscopic removal attempt.

\section{Disclosure Statement}

All authors have read and approved the manuscript and deny conflicts of interest.

\section{Author Contributions}

C.T., A.L.A., and I.C. were involved in the management of the case. The manuscript was prepared by C.T. and was vetted by all.

\section{References}

1 Clavien P, Richon J, Burgan S, et al: Gallstone ileus. Br J Surg 1990;77: 737-742.

2 Reisner R, Cohen J: Gallstone ileus: a review of 1,001 reported cases. Am Surg 1994;63:441-446.

3 Rigler L, Borman C, Noble J: Gallstone obstruction: pathogenesis and roentgen manifestations. JAMA 1941;117:1753-1759.

-4 Nuño-Guzmán CM, Marín-Contreras M, Figueroa-Sánchez M, et al Gallstone ileus, clinical presentation, diagnostic and treatment approach. World J Gastrointest Surg 2016;8:65-67. 